\title{
Gas-Atomized Al 6061 Powder: Phase Identification and Evolution During Thermal Treatment
}

\author{
KYLE TSAKNOPOULOS, ${ }^{1}$ CAITLIN WALDE,${ }^{1}$ \\ VICTOR CHAMPAGNE JR., ${ }^{2}$ and DANIELLE COTE ${ }^{1,3}$
}

1.-Worcester Polytechnic Institute, Worcester, MA 01609, USA. 2.-US Army Research Laboratory, Aberdeen Proving Ground, Aberdeen, MD 21005-5069, USA. 3.-e-mail: dlcote2@wpi.edu

\begin{abstract}
Metal additive manufacturing processes often use gas-atomized powder as feedstock, but these processes use different methods for consolidation. Depending on the consolidation temperature, secondary phases may be retained during processing, making it important to understand powder microstructure prior to consolidation. Commercial alloy compositions are typically used for these powders because they have been widely studied and qualified; however, the microstructure of the powder form of these compositions has not been studied. This paper aims to understand the commercial Al 6061 powder: how the internal microstructure of the powder differs from wrought both in the as-manufactured and thermally-treated conditions. A specific focus is put on the Mg-rich phases and their morphologies. This was accomplished through transmission electron microscopy, scanning transmission electron microscopy, and energy dispersive x-ray spectroscopy. Both the size and morphology of the phases in the powder differ greatly from those in the wrought form.
\end{abstract}

\section{INTRODUCTION}

Commercial alloy compositions are often used to create powders that are used for feedstock for many metal additive manufacturing (AM) processes. In doing so, additional material qualification for a new alloy can be avoided, making qualification for use more feasible. While these compositions have been widely studied in the wrought or cast form, limited work has been carried out to analyze the microstructure of the powder form of these alloys.

Some metal AM techniques use gas-atomized $\mathrm{Al}$ alloy powders as feedstock. During the gas-atomization process, liquid droplets undergo rapid solidification, experiencing cooling rates on the order of $10^{4}-10^{5 \circ} \mathrm{C} / \mathrm{s} .{ }^{1}$ This cooling rate is radically different that those experienced by similar alloys in a casting process, which are on the order of $10^{-1}-10^{2 \circ} \mathrm{C} / \mathrm{s}$, leading to different microstructures and resultant properties in powders as compared to their cast or wrought counterparts. ${ }^{1}$
With research on wrought parts, the structure has been widely studied before and after various thermal treatments and mechanical processes. ${ }^{2}$ However, with the advent of AM, the focus was first on creating the process and then on optimizing the processing parameters for the consolidated part, and it is only in recent years that research has been conducted analyzing the effects of the feedstock on the consolidated parts. ${ }^{3-10}$

Many metal AM techniques that utilize powder as feedstock employ melting as a means of consolidating the feedstock into a solid material. These processes use different methods to melt the feedstock, for example, electron beams or lasers, which affect the melt pool temperature ${ }^{11,12}$ and differences in melt pool temperature can influence the microstructure. Many secondary phases can have extremely high melting points, higher than that of the matrix of the material, so, even though the powder is melted, not all of the secondary phases may melt. ${ }^{2}$ With this in mind, the secondary phases could remain in the melt pool, depending on the AM 
processing temperature (laser, e-beam, etc.), and thus be retained in the solidified consolidated structure.

Solid-state metal additive manufacturing (SSMAM) techniques are gaining exposure because they do not have the severe cooling gradients seen in liquid-state manufacturing techniques. In these SS-MAM processes, the feedstock is not melted, and consequently the majority of the features of the feedstock powder are retained or even improved upon during consolidation. ${ }^{13}$ With this in mind, it is important to understand the characteristics of the feedstock powder prior to use in SS-MAM processes, given that the rapidly solidified microstructure of the feedstock powders will carry over into the final consolidation.

To date, little research has been carried out to evaluate the properties and microstructure of rapidly solidified powders. Rokni et al. performed some in-depth analysis of as-atomized aluminum powders. They analyzed both the size distribution and shape, as well as the internal microstructure utilizing scanning electron microscopy (SEM), transmission electron microscopy (TEM), and electron backscatter diffraction. They reported that gasatomized aluminum particles show surface grain features in the $1-4 \mu \mathrm{m}$ range, with a similar structure internally accompanied by some solute segregation. $^{3-6}$ Additionally, they showed that grains are typically equiaxed with some residual stresses. $^{3}$

As Rokni et al. have shown, the structure present in the powders is also present in the consolidated part. With this in mind, Sabard et al. applied a heat treatment to the as-atomized powders prior to use in cold spray consolidation. ${ }^{7}$ They found that, with a heat treatment of $4 \mathrm{~h}$ at $450^{\circ} \mathrm{C}$, particle deformation was enhanced, leading to improved particle-substrate bonding and thicker coatings. Additionally, they found that the thermally-treated powders had a reduction in solute segregation and a higher porosity than the as-atomized condition. The authors also observed the formation of some needle-like precipitates in the thermally-treated condition that were not present in the as-manufactured condition. The chosen treatment temperature was based on commercially used treatments for wrought components, and no work has been carried out to identify treatments specifically designed for powders.

Although Rokni et al. have performed extensive microstructural analysis of the as-atomized microstructure in relation to its presence in the consolidated structure, they, and others, have not identified the specific phases present in the asatomized structure. Adkins and Tsakiropoulos also identified the major intermetallic present in their Al-Cr-Zr-Mn powders $\left(\mathrm{Al}_{13} \mathrm{Cr}_{2}\right)$ but did not evaluate the range of possible phases. ${ }^{8}$ Sabard et al. noted that analysis in an SEM is not sufficient to identify phases present in gas-atomized powder due to the low resolution. ${ }^{9}$ Walde et al. evaluated the microstructural evolution of $\mathrm{Al} 6061$ throughout a solution treatment, but only showed trends in the Mg-rich and Fe-rich phases and did not identify phases. ${ }^{10}$ Their microstructural evaluation utilized SEM, but the interaction volume of the SEM beam limits the phase identification analysis that is possible.

Due to the smaller beam interaction volume, TEM, scanning transmission electron microscopy (STEM), and energy dispersive x-ray spectroscopy (EDS) in a TEM can more accurately identify the phases present beyond the current level of understanding. Fundamentally, this work employs TEM, STEM, and EDS-TEM to build upon the groundwork laid by Walde et al. in understanding the microstructures and secondary phases of gas-atomized Al 6061 feedstock powders. ${ }^{10}$

In wrought form, $\mathrm{Al} 6061$ is a heat-treatable aluminum alloy with the primary strengthening sequence $\beta^{\prime \prime} \rightarrow \beta^{\prime} \rightarrow \beta\left(\mathrm{Mg}_{2} \mathrm{Si}\right)$, moving from needles, to rods, to equilibrium plates or cubes during treatment. ${ }^{14,15} \mathrm{~A}$ typical heat treatment for this alloy consists of a solution treatment step to create a homogenous solid solution, a rapid quench to retain the metastable microstructure, an aging step to evenly precipitate uniformly-sized strengthening phases, and an optional working step. It is important that the first step successfully reaches maximum solid solution in order to achieve an optimal distribution of precipitates during the following aging step. ${ }^{2}$ Beta $\left(\mathrm{Mg}_{2} \mathrm{Si}\right)$ is typically $25 \mu \mathrm{m}$ to begin with, dissolves during treatment, then reforms during aging at around $10 \mathrm{~nm}$. These phases may or may not fully dissolve during treatment. ${ }^{16}$

In summary, this work characterizes gas-atomized $\mathrm{Al} 6061$ in both the as-manufactured and thermally-treated conditions. Emphasis is given to identifying the phases present, more specifically the Mg-rich phases (the strengthening phase in the $\mathrm{Al}$ 6061 alloy), as they differ in morphology from those present in the wrought counterparts. This is accomplished through extensive TEM analysis.

\section{METHODS}

\section{Powder}

For this research, gas-atomized $\mathrm{Al} 6061$ powder manufactured by Valiment (Stockton, CA, USA) was used. The initial batch was classified by size using a mechanical sieving method in compliance with ASTM E11 and divided into seven particle size categories. Size category 38-45 $\mu \mathrm{m}$, was chosen for the analysis with $d_{10}$ of $32 \mu \mathrm{m}, d_{50}$ of $41 \mu \mathrm{m}$, and $d_{90}$ of $54 \mu \mathrm{m}$. The chemical composition of this powder was found using direct current plasma emission spectroscopy (ASTM E1097-12) and can be found in Table I, and is in compliance with $\mathrm{Al} 6061$ (ASTM B209). ${ }^{17,18}$ 
Table I. Al 6061 powder chemical composition analysis compared to ASTM B209

\begin{tabular}{lcc}
\hline Element & Reviewed powder wt.\% & ASTM standard ${ }^{\mathbf{1 8}}$ wt.\% $^{\text {Magnesium }}$ \\
\cline { 2 - 3 } Milicon & 0.950 & $0.80-1.20$ \\
Iron & 0.490 & $0.40-0.80$ \\
Copper & 0.270 & $<0.70$ \\
Oxygen & 0.250 & $0.15-0.40$ \\
Chromium & 0.100 & - \\
Zinc & 0.087 & $0.04-0.35$ \\
Manganese & 0.035 & $<0.25$ \\
Titanium & 0.034 & $<0.15$ \\
Other & 0.024 & $<0.15$ \\
Aluminum & - & $<0.15$ \\
\hline
\end{tabular}

\section{Modeling}

The computational thermodynamic and kinetic modeling software, Thermo-Calc (Stockholm, Sweden) was used to provide insight into the secondary phases present with the given $\mathrm{Al} 6061$ alloy composition, as well as information about their stability at different treatment temperatures. The TCAL5 database was used to create an equilibrium diagram and a non-equilibrium Scheil solidification diagram of the exact composition of the alloy under investigation for comparison with the powder microstructure.

\section{Treatment}

With the goal of creating a homogenous microstructure, a temperature of $530^{\circ} \mathrm{C}$ was chosen, which allowed for dissolution of secondary phases without melting the powder. ${ }^{2}$ The samples were treated for 60 min using a differential scanning calorimeter (DSC) (TA Instruments Discovery DSC with LN2P cooler) with a heating rate of $50^{\circ} \mathrm{C} / \mathrm{min}$ to $530^{\circ} \mathrm{C}$, held at that temperature for $60 \mathrm{~min}$, and then quenched at a rate of $120^{\circ} \mathrm{C} / \mathrm{min}$ in a nitrogen environment. ${ }^{10}$

\section{Characterization}

For TEM imaging, samples were created using a gallium focused ion beam (FIB) (FEI Helios 660 Nanolab and FEI Scios Dual Beam FIBs). Powder was distributed on carbon tape on an SEM stub for FIB sectioning. This was done by applying a protective Pt layer on the top surface of the chosen powder particle (approximately $40 \mu \mathrm{m} \times 1 \mu \mathrm{m} \times 1$ $\mu \mathrm{m})$. Material on either side of the Pt layer was then removed by milling perpendicular to the top surface of the Pt layer. This produced a parallel-sided slice of the powder particle. This slice was then lifted out and attached to a Mo omni-grid. Then it was thinned to a thickness of approximately $100 \mathrm{~nm}$ with a final finish of $5 \mathrm{kV}$ to remove surface stresses. For elemental quantification analysis using EDS, thinner samples were needed to remove the interaction signal from other phases and the matrix behind the desired phase; smaller sections of the large sample were taken for further thinning for this analysis.

TEM and STEM images were taken using a Probe-corrected FEI Titan Themis 300 S/TEM with ChemiSTEM technology at an accelerating voltage of $300 \mathrm{kV}$. EDS was completed using a Super-X EDS system at $300 \mathrm{kV}$.

\section{Image Analysis}

In order to quantify the secondary phases present, the image analysis software Olympus Stream was used to segment the images using contrast differences between the phases and the matrix. Typical images of this analysis can be seen in Fig. 1, which shows typical TEM images for both the asmanufactured and thermally-treated samples. The Mg-rich phases contrast darker than the matrix in the TEM high-angle annular dark-field (HAADF) images while the Fe-rich phases are contrast lighter.

\section{RESULTS AND DISCUSSION}

\section{Modeling}

The diagrams created in Thermo-Calc provide insight into which phases are expected given the alloy composition, and serve as a starting point for phase identification in the powder microstructure. Figure $2 \mathrm{a}$ shows the equilibrium phases present in the $\mathrm{Al} 6061$ composition as a function of temperature. This shows the stability of the different secondary phases, which is especially useful to know during thermal treatment. Since these powders are gas-atomized, they are rapidly solidified and are thus not considered to be in an equilibrium state. Given that, it is expected that the phases present in the as-manufactured powder microstructure would more closely match that predicted by the Scheil solidification diagram (Fig. 2b).

The equilibrium and non-equilibrium phases predicted by the Thermo-Calc models for as-manufactured and thermally treated conditions are compiled 

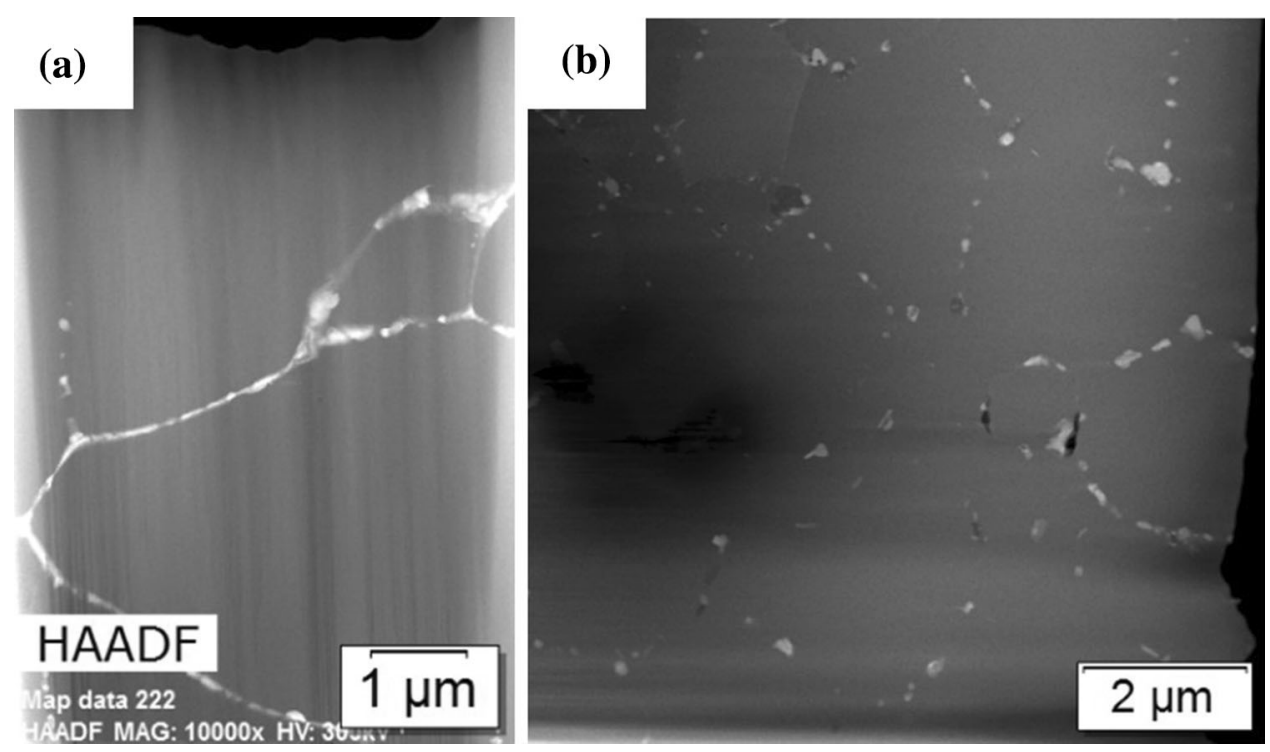

Fig. 1. Typical images used for secondary phase fraction analysis: (a) TEM-HAADF of as-manufactured Al 6061 particle lamella, (b) TEM HAADF of thermally treated Al 6061 particle lamella.
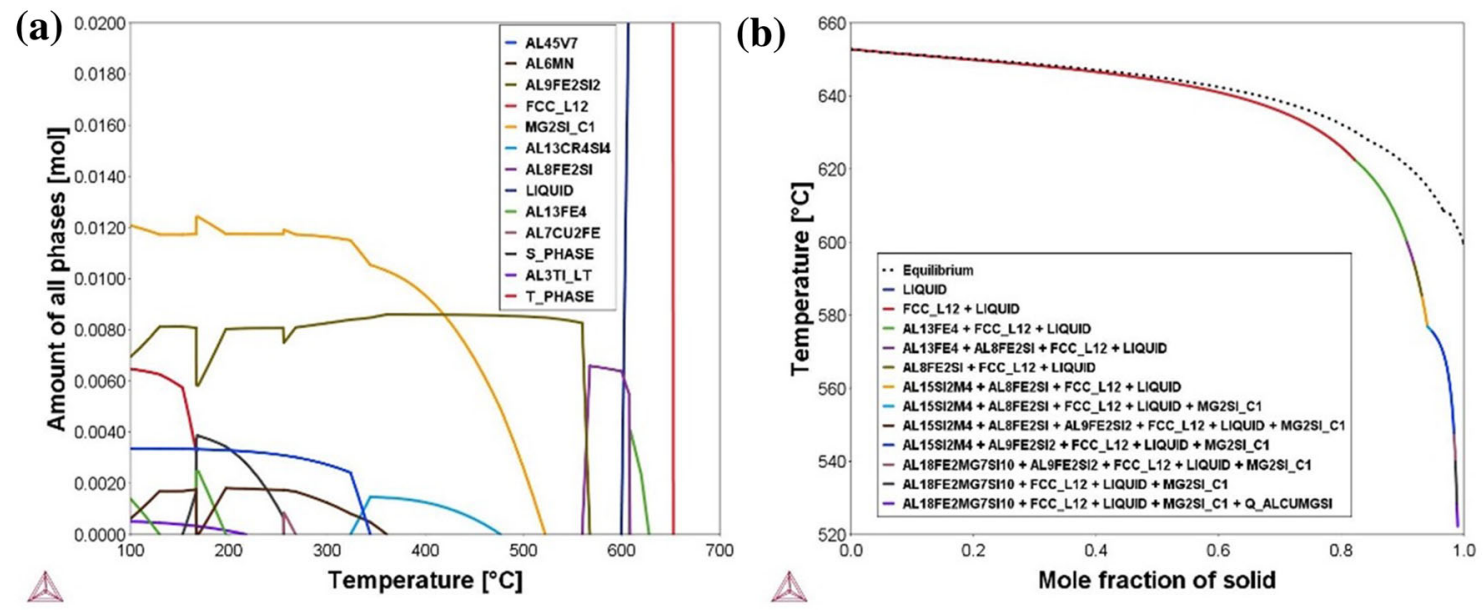

(c)

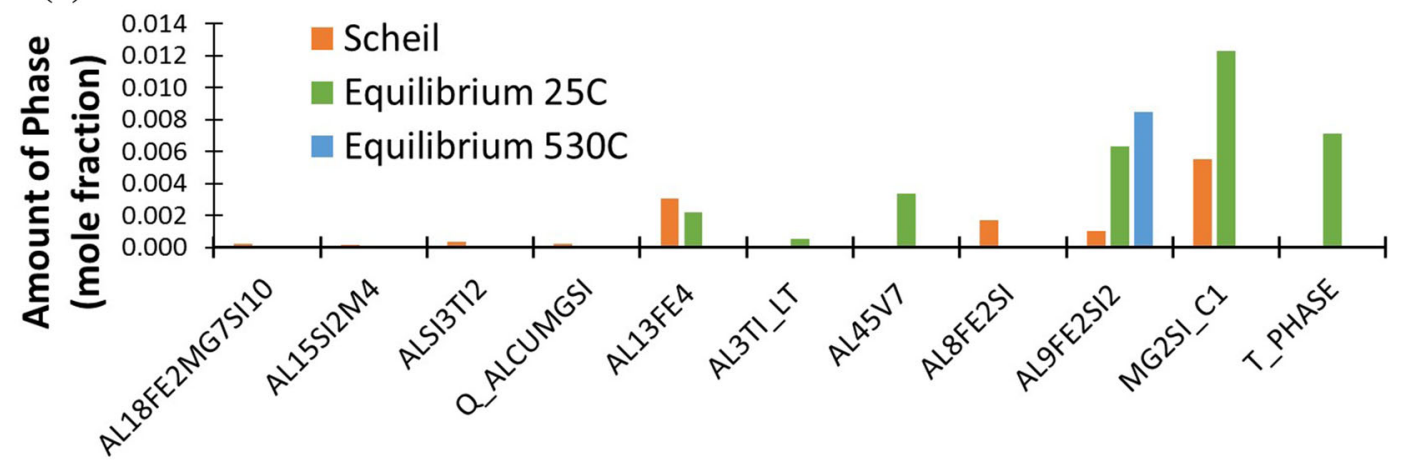

Fig. 2. (a) Equilibrium diagram from Thermo-Calc software, (b) Scheil diagram from Thermo-Calc software, (c) amount of each possible phase as predicted by Thermo-Calc software at varying conditions.

in Fig. 2c. This demonstrates the predicted phases in the as-manufactured powder for rapid solidification (Scheil results), the phases expected if the initial powder were at equilibrium (equilibrium results at $25^{\circ} \mathrm{C}$ ), and the phases expected after thermal treatment of the powder (equilibrium 

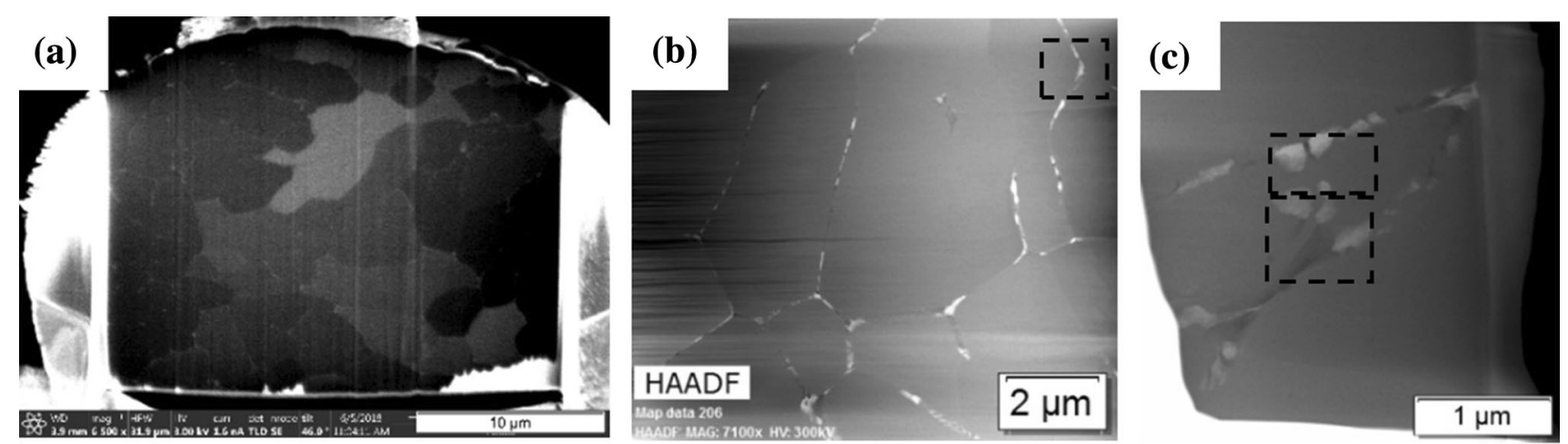

Fig. 3. Overview images of as-manufactured Al 6061: (a) SEM, (b) TEM-HAADF, (c) increased magnification HAADF from (b). Outlined regions show where further analysis will be highlighted.

results at $\left.530^{\circ} \mathrm{C}\right)$. The Scheil results predict the presence of $\mathrm{Al}_{15} \mathrm{Si}_{2}(\mathrm{Fe}, \mathrm{Mn})_{4}, \quad \mathrm{Q}(\mathrm{AlCuMgSi})$, $\mathrm{Al}_{18} \mathrm{Fe}_{2} \mathrm{Mg}_{7} \mathrm{Si}_{10}, \quad \mathrm{AlSi}_{3} \mathrm{Ti}_{2}, \quad \mathrm{Al}_{9} \mathrm{Fe}_{2} \mathrm{Si}_{2}, \quad \mathrm{Al}_{8} \mathrm{Fe}_{2} \mathrm{Si}$, $\mathrm{Al}_{13} \mathrm{Fe}_{4}$ and $\mathrm{Mg}_{2} \mathrm{Si}$, in order of increasing abundance in the as-manufactured powder microstructure, with the most prominent phases being $\mathrm{Mg}_{2} \mathrm{Si}$ and $\mathrm{Al}_{13} \mathrm{Fe}_{4}$. The equilibrium results at $25^{\circ} \mathrm{C}$ predict the presence of $\mathrm{Al}_{3} \mathrm{Ti}, \mathrm{Al}_{13} \mathrm{Fe}_{4}, \mathrm{Al}_{45} \mathrm{Cr}_{7}, \mathrm{Al}_{9} \mathrm{Fe}_{2} \mathrm{Si}_{2}$, TPhase, and $\mathrm{Mg}_{2} \mathrm{Si}$, in order of increasing abundance. Here, the most prominent phases were $\mathrm{Al}_{9} \mathrm{Fe}_{2} \mathrm{Si}_{2}$, TPhase, and $\mathrm{Mg}_{2} \mathrm{Si}$. The equilibrium results at $530^{\circ} \mathrm{C}$ show only the presence of $\mathrm{Al}_{9} \mathrm{Fe}_{2} \mathrm{Si}_{2}$, as the previously mentioned phases are no longer stable at that temperature and will have dissolved back into the matrix.

These results can be used to determine the phases present in the powder microstructure, but it is important to note that the data used to create the Thermo-Calc databases were taken from cast or wrought samples, rather than powder samples. Given this, it is possible that there are discrepancies between the powder microstructure and the predicted models, as the kinetics for powders are significantly faster than their wrought counterparts due to their smaller size.

\section{As-manufactured Powder}

Once sectioned and thinned, the samples were analyzed by TEM-HAADF, EDS maps and EDS point quantifications. While thinner samples were specifically extracted to remove interaction effects from the matrix or overlapping phases, there were still many instances where the secondary phases were thinner than the lamella. This was taken into consideration during analysis of the point quantifications; if there is matrix behind the analyzed phase, the quantification will show a higher $\mathrm{Mg}$ content, as the matrix is richer in $\mathrm{Mg}$ than in Si. Alternatively, if there is an Fe-rich phase behind the analyzed phase, the quantification will show a lower $\mathrm{Mg}$ content, as the Fe-rich phases contain more Si than Mg. With this in mind, all of the Mgrich phases were found to be $\mathrm{Mg}_{2} \mathrm{Si}$ with varying morphologies.
Figure 3 displays images of as-manufactured powder. Figure 3a shows an SEM image of an asmanufactured powder particle. The channeling contrast reveals clusters of similarly oriented subgrains with phases at the sub-grain boundaries, consistent with what is reported in the literature for powders. $^{3-10}$ Figure $3 \mathrm{~b}$ shows a low-magnification TEM-HAADF image of a similar sample. Figure 3c shows a higher magnification TEM-HAADF image of an as-manufactured sample. Note the continuous nature of the phases at the sub-grain boundaries. These, and similar microstructures, were analyzed in the image analysis software to determine the phase fraction of the secondary phases. It was found that there were $1.62 \%$ (area) $\mathrm{Mg}_{2} \mathrm{Si}$ and $3.42 \%$ (area) Fe-rich phases present in the as-manufactured samples.

Additionally, EDS point analysis quantification was performed at multiple points at the subgrain interiors to determine the matrix composition. The average matrix composition was found to have 97.56 wt. $\% \mathrm{Al}, 1.16$ wt. $\% \mathrm{Mg}, 0.04$ wt.\% $\mathrm{Fe}$, and 0.02 wt.\% Si with trace amounts of the remaining elements. The solubility limit of $\mathrm{Mg}$ in $\mathrm{Al}$ is less than 0.5 wt. $\%$ at room temperature. ${ }^{19}$ This demonstrates that the $\mathrm{Mg}$ composition in the $\mathrm{Al}$ matrix in these powders is higher than the solubility limit. This confirms the supersaturated nature of the powders due to rapid solidification.

Figure 4 shows a HAADF micrograph of a triple point boundary with elemental EDS maps for $\mathrm{Al}$, $\mathrm{Cu}, \mathrm{Fe}, \mathrm{Mg}$, and $\mathrm{Si}$. Figure $4 \mathrm{~g}$ shows the highlighted region of Fig. 4a magnified, where the atomic lattice of the precipitate can be seen as incoherent with that of the matrix. From the elemental maps, it can be concluded that this is a rod-like $\mathrm{Mg}_{2} \mathrm{Si}$ particle with an Fe-rich phase surrounding it. This morphology appears to be unique to powders. The composition from point analysis combined with the incoherent nature of the phase boundary indicates that the phase is $\mathrm{Mg}_{2} \mathrm{Si}$ and not a metastable precursor.

Figure 5a, b, c, d, e, and f shows a HAADF image of $\mathrm{Mg}_{2} \mathrm{Si}$ and Fe-rich particles along a grain 

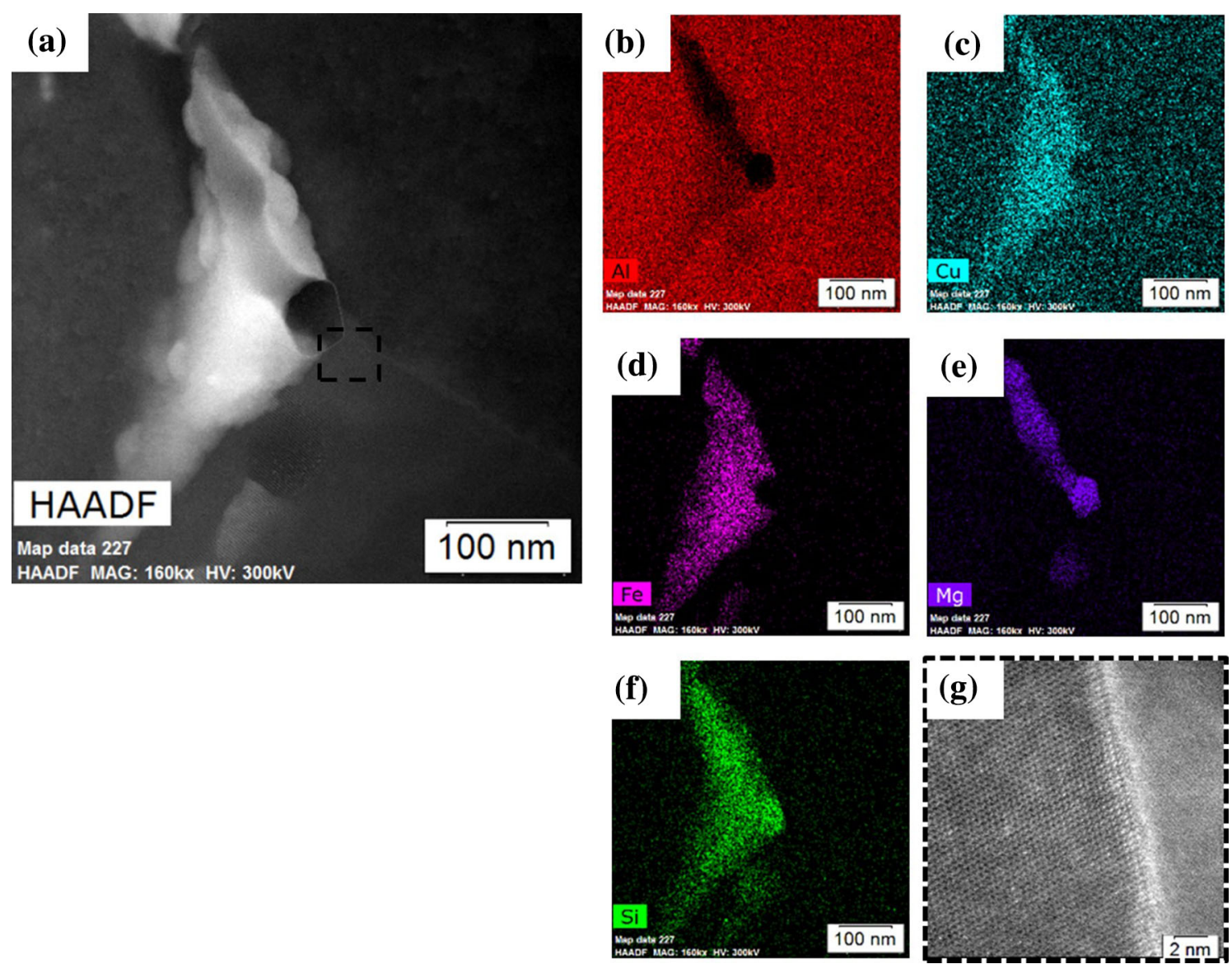

Fig. 4. (a) HAADF image of a triple point in as-manufactured Al 6061. Elemental EDS maps for: (b) Al, (c) Cu, (d) Fe, (e) Mg, (f) Si. (g) Highmagnification HAADF of highlighted region in (a).

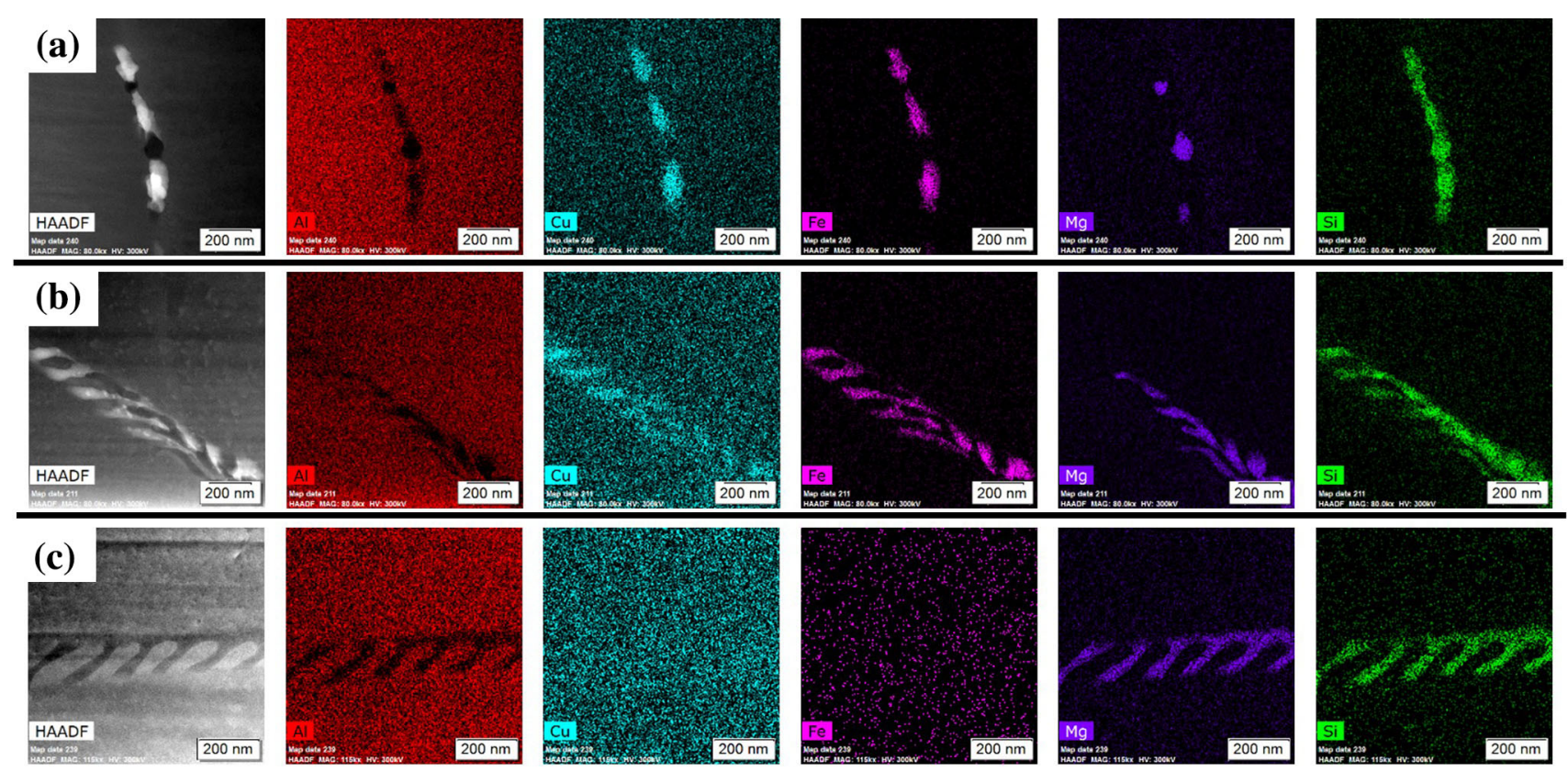

Fig. 5. Elemental EDS maps and HAADF images of Mg-rich phases at a boundary in as-manufactured Al 6061: (a) alternating Mg2si and Fe-rich phases (left to right: HAADF image, $\mathrm{Al}, \mathrm{Cu}, \mathrm{Fe}, \mathrm{Mg}, \mathrm{Si}$ ), (b) alternating Mg2si and Fe-rich phases in a different orientation (left to right: HAADF image, $\mathrm{Al}, \mathrm{Cu}, \mathrm{Fe}, \mathrm{Mg}, \mathrm{Si}$ ), (c) unique Mg2si morphology at a boundary phases (left to right: HAADF image, $\mathrm{Al}, \mathrm{Cu}, \mathrm{Fe}, \mathrm{Mg}, \mathrm{Si}$ ). 

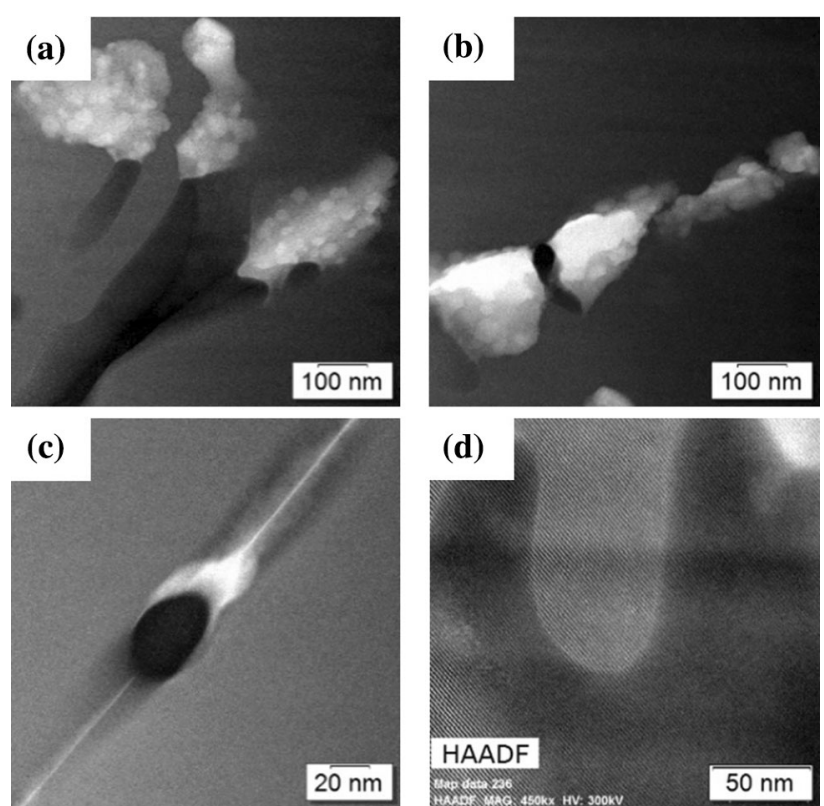

Fig. 6. Additional morphologies of $\mathrm{Mg} 2 \mathrm{Si}$ in as-manufactured $\mathrm{Al}$ 6061: (a) Fe-rich phase on $\mathrm{Mg}_{2} \mathrm{Si}$, (b) alternating Fe-rich and $\mathrm{Mg}_{2} \mathrm{Si}$ on a boundary, (c) $\mathrm{Mg}_{2} \mathrm{Si}$ on a boundary, (d) atypical $\mathrm{Mg}_{2} \mathrm{Si}$ morphology.

boundary, along with elemental EDS maps for Al, $\mathrm{Cu}, \mathrm{Fe}, \mathrm{Mg}$, and $\mathrm{Si}$. It can be seen that $\mathrm{Si}$ is present in both the $\mathrm{Mg}$ - and Fe-rich phases. These have different morphologies than the $\mathrm{Mg}_{2} \mathrm{Si}$ and Fe-rich phase in Fig. 4.

Figure 5g, h, i, j, l, and $\mathrm{m}$ shows a HAADF image of $\mathrm{Mg}_{2} \mathrm{Si}$ and $\mathrm{Fe}$-rich phases in a lamellar structure along a boundary. This microstructure is consistent with that of cellular precipitation, which is more likely to be the mechanism of precipitation in nonequilibrium systems. This morphology of $\mathrm{Mg}_{2} \mathrm{Si}$ is particularly different than seen in castings. A perpendicular view of the cellular precipitates can be seen in Fig. 5a, b, c, d, e, and f.

Figure 5n, o, p, q, r, s, and t shows a HAADF image of $\mathrm{Mg}_{2} \mathrm{Si}$ in another cellular structure with the Al-matrix, along with elemental EDS maps for $\mathrm{Al}, \mathrm{Cu}, \mathrm{Fe}, \mathrm{Mg}$, and $\mathrm{Si}$. Here, there is no Fe-rich phase interacting with the $\mathrm{Mg}_{2} \mathrm{Si}$, so this is yet another unique morphology.

Figure 6 shows additional morphologies of the $\mathrm{Mg}_{2} \mathrm{Si}$ (dark-contrasting phase) present in the asmanufactured powders at various magnifications. All of the unique morphologies seen in the asmanufactured powders can be attributed to the rapidly solidified, non-equilibrium structure.

The thermodynamic and kinetic models in Fig. 2 predict that other Mg-containing phases should be present in the as-manufactured condition; however, $\mathrm{Mg}_{2} \mathrm{Si}$ is the only $\mathrm{Mg}$-rich phase seen in these gasatomized $\mathrm{Al} 6061$ powders. The discrepancy stems from the models being created using data for wrought conditions. This further emphasizes the need to understand powders in both models and experiments.

\section{Thermally-Treated Powder}

Figure 7a shows an SEM image of a thermallytreated powder particle. Figure 7b shows a lowmagnification TEM image of a similar sample. Figure 7c shows a higher-magnification TEM image of a thermally treated sample. Note the discrete phases, in contrast to the continuous nature of the phases present in the as-manufactured sample. This structure is consistent with what is reported in the literature for powders. ${ }^{3-10}$

Additionally, note the qualitative decrease in the dark-contrasting $\mathrm{Mg}_{2} \mathrm{Si}$. These, and similar micrographs, were used in the image analysis software to determine the phase fraction of the $\mathrm{Mg}_{2} \mathrm{Si}$. It was found that there were $0.81 \%$ (area) $\mathrm{Mg}_{2} \mathrm{Si}$, a decrease from the as-manufactured samples, and $4.4 \%$ (area) Fe-rich phases, an increase from the asmanufactured sample.

Figure $7 \mathrm{~d}$, e shows examples of two $\mathrm{Mg}_{2} \mathrm{Si}$ morphologies in the thermally-treated condition. Figure $7 \mathrm{~d}$ shows an $\mathrm{Mg}_{2} \mathrm{Si}$ particle at a prior triple point, while Fig. $7 \mathrm{e}$ shows a much smaller $\mathrm{Mg}_{2} \mathrm{Si}$ particle with an Fe-rich phase. Based on Fig. 2, all $\mathrm{Mg}_{2} \mathrm{Si}$ should dissolve at the treatment temperature. It is hypothesized that the $\mathrm{Mg}_{2} \mathrm{Si}$ at the triple points spheroidizes to a more equilibrium plate-like shape prior to dissolving, while $\mathrm{Mg}_{2} \mathrm{Si}$ on the grain boundaries dissolves. The point quantification analysis, along with the semi-coherent atomic lattice structure seen in Fig. 7d, indicates that these phases are $\mathrm{Mg}_{2} \mathrm{Si}$ rather than a metastable precursor.

A longer treatment time is necessary to fully dissolve all the $\mathrm{Mg}_{2} \mathrm{Si}$ and reach the equilibrium structure predicted by Fig. 2a. However, it has been shown in SEM studies that the Fe-rich phases continue to grow, and thus results in a more heterogeneous microstructure. ${ }^{10}$ Treatment times must be optimized for each application, depending upon whether the goal is a homogenous microstructure or the complete dissolution of $\mathrm{Mg}_{2} \mathrm{Si}$. Fe-rich phases tend to act as nucleation sites for cracks and have been known to cause poor wear properties; however, at least partially solutionizing the powder has been shown to increase ductility during the solid-state metal AM process cold spray. ${ }^{4,20}$ It has been hypothesized that the Fe-rich phases control the mechanical properties of this powder, but, given the amount of different types of Fe-rich phases predicted by Fig. 2, and the fact that model predictions were inaccurate for $\mathrm{Mg}_{2} \mathrm{Si}$, identification of the Fe-rich phases is an extensive study that will be reported separately. ${ }^{10}$

The thermodynamic and kinetic models in Fig. 2 predict that the $\mathrm{Mg}_{2} \mathrm{Si}$ should be fully dissolved at $530^{\circ} \mathrm{C}$; however, some $\mathrm{Mg}_{2} \mathrm{Si}$ is still present in these thermally-treated gas-atomized $\mathrm{Al} 6061$ powders at this temperature. The discrepancy stems from the models being created using data for wrought conditions, and also the treatment time not being long 

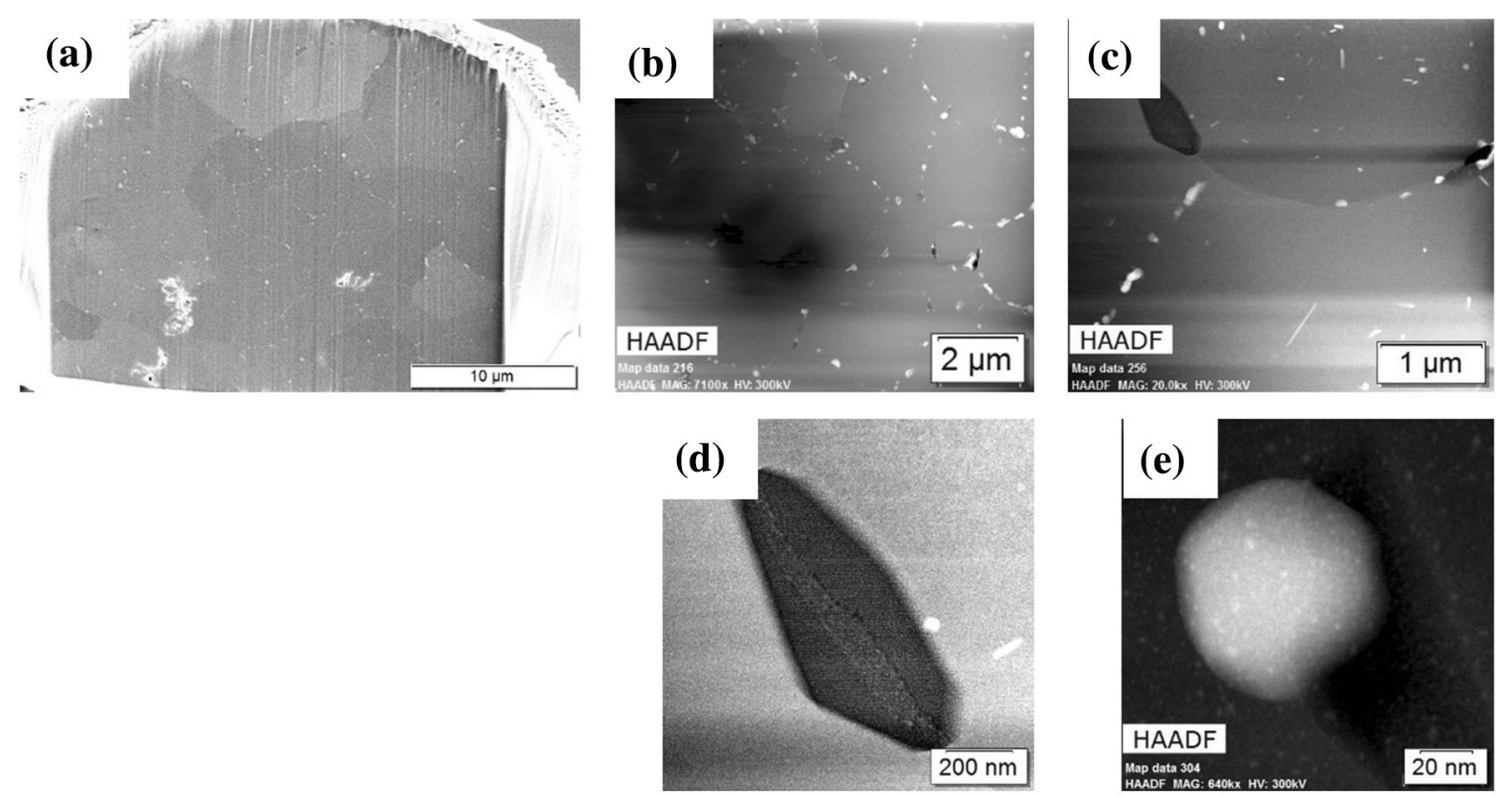

Fig. 7. Overview images of thermally treated Al 6061: (a) SEM, (b) TEM HAADF, (c) increased magnification HAADF of similar sample, (d) Mg2Si of plate-like morphology, (e) Mg2Si dissolving.

enough to reach equilibrium. This further emphasizes the need to understand powders in both models and experiments.

Previous work carried out by Walde et al. reported phase fractions for the $\mathrm{Mg}$ - and $\mathrm{Fe}$-rich phases in powders in the same conditions as studied here; however, the work is performed here in TEM rather than SEM. ${ }^{10}$ Due to the smaller interaction volume, TEM can provide better insights into the amount of phases present than can SEM, as some of the phases present are smaller than the interaction volume of the SEM beam, a limitation acknowledged by the authors. They reported no measurable Mg-rich phases and 16\% (area) Fe-rich phases in the as-manufactured powder, with less than $1 \%$ (area) Mg-rich phases and $4.5 \%$ (area) Fe-rich phases in the thermally-treated powder. Both the numbers and trends vary greatly from the results reported here. This discrepancy is likely due to the limitations of the SEM beam as previously discussed; TEM analysis revealed many precipitates that are too small for an SEM to detect.

In general, the $\mathrm{Mg}_{2} \mathrm{Si}$ seen in these powders varies in both size and morphology from what is reported in the literature for wrought $\mathrm{Al}$ 6061. In the literature for wrought $6 \mathrm{xxx} \mathrm{Al}$ alloys, $\mathrm{Mg}_{2} \mathrm{Si}$ is stated to exist as plates or cubes, with precursors $\beta^{\prime}$ and $\beta^{\prime \prime}$ existing as rods and needles, respectively. None of these structures were observed in the asmanufactured powder, and equilibrium plate-like $\mathrm{Mg}_{2} \mathrm{Si}$ was seen in varying amounts in the thermally-treated sample. Perhaps in shorter treatment time increments (20 min, $40 \mathrm{~min})$, the metastable phases could be seen. In powders, the as-manufactured sample is smaller, and, with the higher cooling rate during solidification, the grains are smaller. Because of this, the boundaries are smaller, which significantly limits the size of the precipitates, making those present in the powder around 10 times smaller than those present in the wrought condition.

\section{CONCLUSION}

Through extensive TEM analysis, this work demonstrates how the internal microstructure of commercial alloy compositions in the powder form differ from those present in the wrought condition. Specific focus has been given to the $\mathrm{Mg}_{2} \mathrm{Si}$ phase in the as-manufactured and thermally-treated conditions, as it is the primary strengthening phase in the $\mathrm{Al} 6061$ alloy. It was shown that $\mathrm{Al} 6061$ powder contains $\mathrm{Mg}_{2} \mathrm{Si}$ of highly atypical morphologies in the as-manufactured condition. Once thermally treated, the smaller $\mathrm{Mg}_{2} \mathrm{Si}$ precipitates dissolve and the larger ones spheroidize to the more equilibrium plate- or cube-like structures. This greatly differs from the microstructures seen in the wrought versions of the same commercial alloy composition and from the amounts of $\mathrm{Mg}_{2} \mathrm{Si}$ predicted by thermodynamic and kinetic models.

There is opportunity for further optimization of the thermal treatment for individual applications; it is not possible to achieve a fully homogenous microstructure as the Fe-rich phases grow as the $\mathrm{Mg}_{2} \mathrm{Si}$ dissolves. Identification of those Fe-rich phases will be needed to effectively optimize the thermal treatment parameters and will be reported elsewhere.

\section{ACKNOWLEDGEMENTS}

This work was funded by the United States Army Research Laboratory, Grant \#W911NF-15-2-0024. 
This work was performed in part at the Kostas Advanced Nano-Characterization Facility in Kostas Research Institute at Northeastern University and at the Center for Nanoscale Systems (CNS), a member of the National Nanotechnology Coordinated Infrastructure Network (NNCI), which is supported by the National Science Foundation under NSF Award No. 1541959.

\section{OPEN ACCESS}

This article is distributed under the terms of the Creative Commons Attribution 4.0 International License (http://creativecommons.org/licenses/by/4.0/ ), which permits unrestricted use, distribution, and reproduction in any medium, provided you give appropriate credit to the original author(s) and the source, provide a link to the Creative Commons license, and indicate if changes were made.

\section{REFERENCES}

1. A. Mullis, L. Farrell, R. Cochrane, and N. Adkins, Metall. Trans. B 44, 992 (2013).

2. L. Katgerman and D. Eskin, Handbook of Aluminum: Vol. 1: Physical Metallurgy and Processes, ed. G.E. Totten (Boca Raton: CRC Press, 2003), p. 259.

3. M.R. Rokni, C.A. Widener, and V.R. Champagne, J. Therm. Spray Technol. 23, 514 (2014).

4. M.R. Rokni, C.A. Widener, V.K. Champagne, G.A. Crawford, and S.R. Nutt, Surf. Coat. Technol. 310, 278 (2017).

5. M.R. Rokni, C.A. Widener, O.C. Ozdemir, and G.A. Crawford, Surf. Coat. Technol. 309, 641 (2017).

6. M.R. Rokni, C.A. Widener, G.A. Crawford, and M.K. West, Mater. Sci. Eng. A 625, 19 (2015).
7. A. Sabard, H.L. de Villiers Lovelock, T. Hussain, J. Therm. Spray Technol. 1, 145 (2017).

8. N.J.E. Adkins and P. Tsakiropoulos, Mater. Sci. Technol. 7, 334 (1991).

9. A. Sabard, H.L. de Villiers Lovelock, and T. Hussain, J. Therm. Spray Technol. 27, 145 (2018).

10. C. Walde, D. Cote, V. Champagne, and R. Sisson, J. Mater. Eng. Perform. (2018). https://doi.org/10.1007/s11665-018-35 50-0.

11. L. Sochalski-Kolbus, E. Payzant, P. Cornwell, T. Watkins, S. Babu, R. Dehoff, M. Lorenz, O. Ovchinnikova, and C. Duty, Metall. Mater. Trans. A 46, 1419 (2015).

12. G. Vastola, G. Zhang, Q. Pei, and Y. Zhang, JOM 68, 1370 (2016).

13. V.K. Champagne, The Cold Spray Materials Deposition Process: Fundamentals and Applications (Cambridge, England: Woodhead Publishing Limited, 2007), p. 52

14. D. Chakrabarti and D.E. Laughlin, Prog. Mater Sci. 49, 389 (2004).

15. K. Matsuda, et al., Mater. Sci. Eng. A 262, 232 (1999).

16. J.E. Hatch, Aluminum: Properties and Physical Metallurgy, 1st ed. (Metals Park: American Society for Metals, 1984), pp. 71-103.

17. ASTM E1097-12 Standard Guide for Determination of Various Elements by Direct Current Plasma Atomic Emission Spectrometry, ASTM International, West Conshohocken, PA (2012). https://doi.org/10.1520/E1097-12.

18. ASTM B209-10 Standard Specification for Aluminum and Aluminum-Alloy Sheet and Plate, ASTM International, West Conshohocken, PA (2010). https://doi.org/10.1520/B02 $09-10$.

19. Thermo-Calc Software TCAL5 Aluminum-based Alloys Database version 5. Accessed 15 Aug 2018.

20. S.P. Espezua, C. Baptista, D.F. Laurito, A. Antunes, $S A E$ Technical Papers, (2012). https://doi.org/10.4271/2012-36-0 520. 